\title{
Severe non-exertional rhabdomyolysis from weight loss supplement in sickle cell trait: A perfect storm?
}

\author{
Titilope Olanipekun*1, Valery Effoe ${ }^{1}$, Ganiat Adeogun ${ }^{1}$, Agniezka Gaertig ${ }^{1}$, Myrtle White ${ }^{2}$, Matthew Haney ${ }^{2,3}$ \\ ${ }^{1}$ Department of General Internal Medicine, Morehouse School of Medicine, Atlanta, Georgia, United States \\ ${ }^{2}$ Atlanta Veteran Affairs Medical Center, Decatur, Georgia, United States \\ ${ }^{3}$ Department of General Internal Medicine, Emory School of Medicine, Atlanta, Georgia, United States
}

Received: November 24, 2017

Accepted: January 22, $2018 \quad$ Online Published: February 8, 2018

DOI: $10.5430 /$ crim.v5n $1 \mathrm{p} 35$

URL: https://doi.org/10.5430/crim.v5n1p35

\begin{abstract}
Exertional rhabdomyolysis from sickle cell trait has been documented. Also, cases of rhabdomyolysis from the use of weight loss supplements in the setting of sickle cell trait and exertion have been described. However, the role of sickle cell trait in non-exertional rhabdomyolysis is not clear. We present a case of severe non-exertional rhabdomyolysis from weight loss supplement in a patient with sickle cell trait.

A 45-year-old African American female with sickle cell trait presented to the emergency department with two days history of fatigue and mild breathlessness. She also reported diarrhea and vomiting for five days before presentation. She admitted to taking Garcinia cambogia (a dietary supplement) for weight loss one week prior to the onset of symptoms. She denied alcohol or drug use, rigorous physical activity or trauma.

She was dehydrated on examination. Laboratory values revealed markedly elevated serum creatine phosphokinase (CPK) and creatinine levels. Garcinia cambogia was discontinued and she was hydrated with intravenous fluids. Her CPK and creatinine levels significantly trended down and she was discharged home with no apparent sequelae.

Our patient had multiple episodes of diarrhea and vomiting likely from the use of Garcinia cambogia. We believe she suffered non-exertional rhabdomyolysis from dehydration in the setting of sickle cell trait. Though dietary weight loss supplements are marketed as generally safe, this case suggests otherwise. We emphasize that clinicians routinely inquire about use of these supplements and provide appropriate counseling to patients on the adverse effects, especially among those with sickle cell trait.
\end{abstract}

Key Words: Weight loss, Rhabdomyolysis, Sickle cell trait, Exertion

\section{INTRODUCTION}

Rhabdomyolysis is a condition characterized by muscle breakdown with resultant release of intracellular muscle contents into the circulation. ${ }^{[1]}$ The degree of muscle injury frequently correlates with electrolyte imbalances and acute kidney injury (AKI) which could lead to significant morbid- ity and mortality in affected individuals. ${ }^{[1]}$ The hallmark of rhabdomyolysis is elevated serum muscle enzymes, specifically creatine phosphokinase $(\mathrm{CPK}) .{ }^{[2]}$

Common causes of rhabdomyolysis include extreme physical exertion, extensive tissue injury, metabolic derangements, drugs, and toxins. ${ }^{[1-3]}$ Interestingly, few case reports have

*Correspondence: Titilope Olanipekun; Email: toolanipekun@ gmail.com; Address: Department of General Internal Medicine, Morehouse School of Medicine, Atlanta, Georgia, United States. 
suggested that some dietary weight loss supplements could predispose to rhabdomyolysis. ${ }^{[4-6]}$ It is theorized that ingredients in these products are directly toxic to myocytes and also impair intracellular calcium homeostasis leading to myonecrosis, especially in the setting of concomitant exertion. [7]

The association between sickle cell trait and exertional rhabdomyolysis has been extensively documented. ${ }^{[8-10]}$ Extremes of heat, exercise hyperemia, and hypoxia have been associated with increased risk of exertional rhabdomyolysis in patients with sickle cell trait. ${ }^{[11]}$ Burke et al. reported a case of exertional rhabdomyolysis aggravated by weight loss supplement in a patient with sickle cell trait. ${ }^{[7]}$ However, the role of sickle cell trait in non-exertional rhabdomyolysis with or without other risk factors is not clear.

We present a case of severe non-exertional rhabdomyolysis from suspected weight loss supplement in a patient with sickle cell trait. Available literature is also discussed herein to provide more insight into rhabdomyolysis as it relates to weight loss supplement and sickle cell trait.

\section{Case Presentation}

A 45-year-old African American female veteran with a medical history of sickle cell trait, asthma, and fibromyalgia presented to the emergency department with two days history of generalized body weakness and mild shortness of breath. She also complained of multiple episodes of diarrhea, nausea, and vomiting for about five days before presentation. Review of systems revealed low-grade fever, headache, palpitations, muscle soreness and dark colored urine.

Her medications at presentation were oral bronchodilator inhalers and acetaminophen as needed. She also admitted to taking pure Garcinia cambogia (a dietary supplement) for weight loss; one capsule twice daily for one week prior to presentation. She denied use of any other drugs or supplements. She was not on an exercise regimen and had not been involved in any rigorous physical activity or trauma. Also, there was no history of alcohol use, tobacco smoking or illicit drug use. Physical examination revealed heart rate of 102 beats per minute, regular; blood pressure of $127 / 79 \mathrm{mmHg}$; respiratory rate of 23 breaths per minute; temperature of $36.4^{\circ} \mathrm{C}\left(97.5^{\circ} \mathrm{F}\right)$; and oxygen saturation of $100 \%$ on room air. There was normal air entry in both lungs without any abnormal sounds. The rest of her physical examination was unremarkable. Initial laboratory investigations were notable for markedly elevated levels of blood urea nitrogen $(27 \mathrm{mg} / \mathrm{dl})$, serum creatinine $(1.7 \mathrm{mg} / \mathrm{dl})$, aspartate transaminase (633 units/L) and alanine transaminase (311 units/L). Her serum CPK level was > 16,400 units/L (maximum reportable laboratory cut-off value). Remainder of his metabolic profile, serum lactate dehydrogenase (146 units/L), potassium $(3.7 \mathrm{mEq} / \mathrm{L})$ sodium $(138 \mathrm{mEq} / \mathrm{L})$, total bilirubin $(0.2 \mathrm{mg} / \mathrm{dl})$ and hemoglobin $(13.5 \mathrm{~g} / \mathrm{dl}) \mathrm{lev}-$ els were within the normal limits. Urinalysis (dipstick and microscopy) revealed hematuria with trace red blood cells (<1 RBC per hpf). Nasopharyngeal swab for influenza was negative on reverse transcription-polymerase chain reaction (RT-PCR) assay. Microbiology tests were negative for any infectious process.

She was diagnosed with severe rhabdomyolysis complicated by AKI and treated with aggressive intravenous fluid hydration. Garcinia cambogia was discontinued. By hospital day 5, her serum CPK and creatinine levels had trended down to 3,800 units/L and $0.9 \mathrm{mg} / \mathrm{dl}$ respectively and elevated transaminases significantly improved as well. She was subsequently discharged home with no apparent sequelae and counseled on adverse effects of weight loss supplements.

\section{DisCUSSION AND LITERATURE REVIEW}

Dietary weight loss products come in various forms; tablets, capsules, soft gels and contain an average of ten different ingredients. Common ingredients include dietary fiber, herbs, minerals and botanicals. ${ }^{[12]}$ These products are sold with claims that they reduce appetite, nutrient absorption, body fat, metabolism and ultimately body weight. ${ }^{[12]}$ Despite safety concerns and little or no evidence supporting their efficacy, ${ }^{[13]}$ an estimated $35 \%$ of adults in the US have reportedly used a weight-loss supplement at some point in their lives. ${ }^{[14]}$ Also, many users erroneously perceive these products to be safer than prescription medications and believe they are approved by the Food and Drug Agency (FDA) for use. Common adverse effects associated with weight loss supplements include headache, nausea, upper respiratory tract and gastrointestinal symptoms. More serious complications such as myocardial ischemia, hypertensive crises, liver toxicity, seizures, and rhabdomyolysis have also been reported. ${ }^{[7,15]}$ In a nationally representative sample of emergency department cases from 2004 through 2013, adverse effects from dietary weight loss supplements accounted for an average of 23,000 emergency department visits and 2,000 projected hospitalizations annually. ${ }^{[16]}$

Nausea, vomiting, diarrhea, and rhabdomyolysis experienced by our patient following one week use of Garcinia cambogia, raise concerns for an "exposure-outcome" association. Garcinia cambogia is a tropical fruit commonly found in Asia and parts of Africa which contain hydroxycitric acid (HCA) in its pulp. ${ }^{[17]} \mathrm{HCA}$ is believed to inhibit lipogenesis, suppress food intake, and reduce weight gain. Yet, evidence on its efficacy has been conflicting. Heymsfield et al. in a 
randomized control trial showed that HCA did not have a statistically significant effect on body fat and weight. ${ }^{[18]}$ Common adverse effects that have been attributed to Garcinia cambogia are generally mild; headache, nausea, upper respiratory tract and gastrointestinal symptoms. However, Hines et al. noted severe rhabdomyolysis from two weeks ingestion of $100 \%$ pure Garcinia cambogia in an otherwise healthy adult (hemoglobin genotype not reported). Other similar supplements that have been related to rhabdomyolysis include Hydroxycut4 and Synephrine. ${ }^{\text {[7] }}$

Our patient has sickle cell trait, a common condition among individuals of African ancestry and caused by a mutation in the beta-globin gene resulting in heterozygosity. Affected individuals have heterozygous hemoglobin AS (HbAS); wildtype hemoglobin A as well as hemoglobin S. ${ }^{[10]}$ Unlike sickle cell anemia, a more serious disease in which there is two homozygous hemoglobin, individuals with sickle cell trait typically live normal lives. ${ }^{[9]}$ However, there is evidence to support that individuals with sickle cell trait can potentially develop life-threatening complications under certain conditions. Nelson et al. in a retrospective study of US military men with sickle cell trait found significantly higher adjusted risk of exertional rhabdomyolysis (hazard ratio, 1.54; $95 \%$ CI, 1.12 to $2.12 ; p=.008) .{ }^{[10]}$ Likewise, case reports have associated sickle cell trait with muscle cell breakdown and acute kidney injury. ${ }^{[9,11]}$ Further review of the literature suggests that the pathologic link between sickle cell trait and rhabdomyolysis is dehydration which predisposes to sickling of red blood cells in muscle capillaries and consequent ischemia. ${ }^{[11]}$ Patients with sickle cell trait might also be more at risk of severe dehydration due to inherent inability to adequately concentrate their urine and conserve water. ${ }^{[19]}$

Hypercoagulability states have been described in sickle cell trait, though of less severity compared to hemoglobin SS. Systemic micro-particles, proteins $\mathrm{C}$ and $\mathrm{S}$, endothelin-1 (ET-1), thrombin-antithrombin (TAT) complexes, prothrombin fragment 1.2 (F1.2), absolute blood monocyte levels and adrenomedullin (ADM) have been described as markers of hypercoagulable states in sickle cell disease. ${ }^{[20-22]}$ The intensity of anticoagulation using these markers as measures is significantly lesser in hemoglobin AS relative to $\mathrm{SS}^{[22]}$ Interestingly, rhabdomyolysis with concomitant renal failure has reportedly been associated with venous thromboembolism. ${ }^{[23]}$ Severe rhabdomyolysis often causes fatal kidney injury with loss of procoagulant proteins which would promote hypercoagulability. Also, exertion causes endothelial injuries and hemoconcentration both of which increase the risk for thrombosis. ${ }^{[24]}$ It is quite possible that individuals with sickle cell disease, who develop exertional rhabdomyolysis as seen in our patient, may be predisposed to throm-

Published by Sciedu Press boembolic events. More studies should be done to investigate this hypothesis.

Though most cases of rhabdomyolysis documented in sickle cell trait were related to exertion, the inherent urine concentrating defect could easily exacerbate a state of dehydration from non-exertional conditions such as viral gastrointestinal infection, diabetes, sepsis or excessive perspiration. As reported by Eisenbach et al., a 29-year-old African American with sickle cell trait developed severe non-exertional rhabdomyolysis from dehydration during a sauna session. ${ }^{[25]}$ Krieger et al. also suggested that sickle cell trait possibly induced non-exertional rhabdomyolysis in an African - American male who had suffered minor trauma which was not extensive enough to explain the severity of his muscle cell breakdown. ${ }^{[26]}$ Our patient had multiple episodes of diarrhea and vomiting likely from the use of Garcinia cambogia and was dehydrated on examination, which in the setting of sickle cell trait probably precipitated non-exertional muscle cell breakdown.

We strongly associate rhabdomyolysis in this patient with a medical history of sickle cell trait to Garcinia Cambogia use, given the onset of diarrhea and vomiting after starting the medication and severe dehydration noted at presentation. Furthermore, no other common cause was identified; no history of trauma, metabolic derangements, use of other medications and common infections known to cause rhabdomyolysis such as influenza were ruled out. Though, very few cases of non-exertional rhabdomyolysis from Garcinia Cambogia use have been reports, this case suggests that sickle cell trait might be a contributory risk factor creating a perfect storm. Since case reports and series form the bulk of most available evidence in the literature, further research is needed to investigate the temporal effect of weight loss dietary supplements and sickle cell trait either as single or composite factors on the incidence of non-exertional rhabdomyolysis.

\section{Conclusion}

Use of weight loss supplements is fairly common in the US adult population especially among women and US military. ${ }^{[27,28]}$ A small percentage of people who use these supplements inform their primary care providers or any health care professional. ${ }^{[27]}$ Though these products are marketed as generally safe, this case and others in the literature suggest otherwise. We emphasize that clinicians routinely inquire about dietary supplement use during patient encounters and provide appropriate counsel on the potential for adverse outcomes especially in patients with sickle cell trait. 


\section{ACKNOWLEDGEMENTS}

We would like to thank the Department of Rheumatology at Emory School of Medicine, Atlanta for evaluating the patient and providing input towards solving the case.

\section{Conflicts of Interest Disclosure}

The authors have no conflicts of interest to declare.

\section{REFERENCES}

[1] Bosch X, Poch E, Grau JM. Rhabdomyolysis and acute kidney injury. N Engl J Med. 2009; 361(1): 62-72. https://doi.org/10.1056/ NEJMra0801327

[2] Melli G, Chaudhry V, Cornblath DR. Rhabdomyolysis: an evaluation of 475 hospitalized patients. Medicine (Baltimore). 2005; 84(6): 377-385. https://doi.org/10.1097/01.md.0000188565.489 18.41

[3] Huerta-Alardín AL, Varon J, Marik PE. Bench-to-bedside review: Rhabdomyolysis - an overview for clinicians. Crit Care. 2005; 9(2): 158-169. https://doi.org/10.1186/cc2978

[4] Dara L, Hewett J, Lim JK. Hydroxycut hepatotoxicity: A case series and review of liver toxicity from herbal weight loss supplements. World J Gastroenterol. 2008; 14(45): 6999-7004. https: //doi.org/10.3748/wjg.14.6999

[5] Elsayed RK, Glisson JK, Minor DS. Rhabdomyolysis associated with the use of a mislabeled "acai berry" dietary supplement. Am J Med Sci. 2011; 342(6): 535-538. https://doi.org/10.1097/MAJ.0b $013 e 31822 \mathrm{c} 0933$

[6] Elizabeth QH, Eleanore De TE, Laura DM, et al. Severe rhabdomyolysis associated with Garcinia cambogia. Clinical Toxicology. 2015; 53(7): 746-747.

[7] Sinert R, Kohl L, Rainone T, et al. Exercise-Induced Rhabdomyolysis. Ann Emerg Med. 1994; 23(6): 1301-1306. https://doi.org/10 .1016/S0196-0644(94) 70356-6

[8] Makaryus J, Catanzaro J, Katona K. Exertional rhabdomyolysis and renal failure in patients with sickle cell trait: is it time to change our approach? Hematology. 2007; 12(4): 349-352. PMid:17654064. https://doi.org/10.1080/10245330701255254

[9] Dincer HE, Raza T. Compartment syndrome and fatal rhabdomyolysis in sickle cell trait. WMJ. 2005; 104(6): 67-71. PMid:16218320.

[10] Nelson DA, Deuster PA, Carter R, et al. Sickle cell trait, rhabdomyolysis, and mortality among U.S. Army soldiers. N Engl J Med. 2016 375(5): 435-442. https://doi.org/10.1056/NEJMoa1516257

[11] Harrelson GL, Fincher a L, Robinson JB. Acute Exertional Rhabdomyolysis and Its Relationship to Sickle Cell Trait. J Athl Train. 1995; 30(4): 309-312. PMid:16558353.

[12] Branas CC, Elliott MR, Richmond TS, et al. Alcohol consumption, alcohol outlets, and the risk of being assaulted with a gun. Alcohol Clin Exp Res. 2009; 33(5): 906-915. https ://doi.org/10.111 $1 / j .1530-0277.2009 .00912 . x$

[13] Considerations S, Food TUS. Dietary Supplements for Weight Loss - Health Professional Fact Sheet. 2017; 1-13.

[14] Pillitteri JL, Shiffman S, Rohay JM, et al. Use of dietary supplements for weight loss in the United States: results of a national survey. Obes (Silver Spring). 2008; 16: 790-796. PMid:18239570. https://doi.org/10.1038/oby.2007.136

[15] Bouchard NC, Howland MA, Greller HA, et al. Ischemic stroke associated with use of an ephedra-free dietary supplement contain- ing synephrine. Mayo Clin Proc. 2005; 80(4): 541-545. https: //doi.org/10.4065/80.4.541

[16] Geller AI, Shehab N, Weidle NJ, et al. Emergency Department Visits for Adverse Events Related to Dietary Supplements. N Engl J Med. 2015; 373(16): 1531-1540. https://doi.org/10.1056/NEJMsa 1504267

[17] Saper RB, Eisenberg DM, Phillips RS. Common dietary supplements for weight loss. Am Fam Physician. 2004; 70(9): 1731-1738. PMid: 15554492.

[18] Heymsfield SB, Allison DB, Vasselli JR, et al. Garcinia cambogia (hydroxycitric acid) as a potential antiobesity agent: a randomized controlled trial. JAMA. 1998; 280(18): 1596-1600. https: //doi.org/10.1001/jama.280.18.1596

[19] Gupta AK, Kirchner KA, Nicholson R, et al. Effects of $\alpha$-thalassemia and sickle polymerization tendency on the urine-concentrating defect of individuals with sickle cell trait. J Clin Invest. 1991; 88(6): 1963-1968. https://doi.org/10.1172/JCI115521

[20] Lawrie AS, Pizzey A, Trompeter S, et al. Procoagulant activity in patients with sickle cell trait. Blood Coagul Fibrinolysis. 2012; 23(4): 268-270. https://doi.org/10.1097/MBC.0b013e32835187f8

[21] Piccin A, Murphy C, Eakins E, et al. Circulating microparticles, protein $\mathrm{C}$, free protein $\mathrm{S}$ and endothelial vascular markers in children with sickle cell anaemia. J Extracell Vesicles. 2015; 4(1). https://doi.org/10.3402/jev.v4.28414

[22] Westerman MP, Green D, Gilman-Sachs A, et al. Coagulation changes in individuals with sickle cell trait. Am J Hematol. 2002; 69(2): 89-94. https://doi.org/10.1002/ajh.10021

[23] Jullian-Desayes I, Roselli A, Lamy C, et al. Rhabdomyolysis with Acute Renal Failure and Deep Vein Thrombosis Induced by Antipsychotic Drugs: A Case Report. Pharmacopsychiatry. 2015; 48(7): 265-267. https://doi.org/10.1055/s-0035-1564088

[24] Meyering C, Howard T. Hypercoagulability in athletes. Curr Sports Med Rep. 2004; 3(2): 77-83. https://doi.org/10.1249/0014 9619-200404000-00005

[25] Eisenbach C, Pohl J, Dikow R, et al. Severe rhabdomyolysis and renal failure triggered by a sauna visit in sickle cell trait: a case report. Clin Nephrol. 2005; 63(3): 229-231. PMid:15786826. https : //doi.org/10.5414/CNP63229

[26] Krieger P, Zapolsky N, Lowery SJ. A case of severe rhabdomyolysis with minor trauma: Is sickle cell trait to blame? Am J Emerg Med 2016; 34(2): 341e3-341e4. https ://doi.org/10.1016/j.ajem .2015 .06 .035

[27] Blanck HM, Khan LK, Serdula MK. Use of nonprescription weight loss products: results from a multistate survey. Jama. 2001; 286(8): 930-935. https://doi.org/10.1001/jama.286.8.930

[28] Knapik JJ, Steelman RA, Hoedebecke SS, et al. A systematic review and meta-analysis on the prevalence of dietary supplement use by military personnel. BMC Complement Altern Med. 2014; 14(1): 143. https://doi.org/10.1186/1472-6882-14-143 